\title{
What does Petroleum, Environment and Biotechnology means to us vis a vis the Profit Equation?
}

\section{Irvin DT Mpofu*}

Animal Science Department, University of Namibia, Namibia

The profit equation tells us that profit is the maximized difference between income and all manner of costs. Maximize income and minimize costs translates to maximization of the utilization of resources the minimization of paying and which unfortunately often leads to even the minimization of the caring for the resources causing environmental degradation. Traditional profit equation is [RevenueExpenses=Profit]. Some schools of thought have redefined this concept into a new profit equation which is based on "PeoplexProcess=Profit". The key issue everyone must advance and promote is finding a compromise between high profitability and low environmental impact.

Maximization is an opportunity which must be transformed into and strength. Minimization of costs/liabilities is a threat which must never be transformed into a weakness.

Petroleum resource means enthalpy (potential energy) and imbedded in the enthalpy is potential entropy. Enthalpy because the potential and ability to do work is virtually vested and guaranteed by the vast petroleum chemical resources which can be used responsibly for the common good of present and future generations. Entropy in that the direct end products of its utilization like carbon dioxide, carbon monoxide, water (mainly as vapor) and indirect end products of industrial processes it supports and cause. All these end products of petroleum utilization produce green house gases (carbon dioxide and water vapor) and obnoxious gases in the form of carbon monoxide. The devil is in the detail. The vast toxic byproducts from huge industries if not controlled and or rehabilitated spells doom for the environment including the continued supply of this vital natural resource.

The environment is the setting of the manifestation of entropy and enthalpy. The environment laterally, ventrally and dorsally is not infinite. It is limited and exhaustible in space and time respectively.

Biotechnology is all about using skills, techniques and knowledge with living things as catalytic agents. These living things (which are mainly microscopic and less macroscopic) provide a vehicle for creating and actualizing a leap in effectiveness and efficiency of utilization of resources of which petroleum is no exception. Effectiveness creates optimum or even maximized value while efficiency creates competence and environmental protection.

Petroleum resources, the environment and biotechnology should be made to operate or be operated in a system or systems within systems characterized by controllable chain reactions. The chain reactions should guarantee continuous improvement in wealth creation, health and poverty reduction in an incremental fashion. Sustainability is imperative if the present and future generations are to actualize the level and measure of their holistic requirements.

How do we then ensure that that maximization of income from the petroleum-environment-biotechnology matrix does not contribute to the demise of mankind in the not too distant future? More enlighten is needed for effectiveness and efficiency thereof. This enlightenment requires primary and secondary data gathering, data cleaning and finally data analysis using standard and sound statistical analysis procedures so that eventually the data is transformed into information.
The information should be specific, useful, verifiable, abundant, realistic and current. Such type of information is key to the decision making process for fostering, commandeering and promoting developmental policies and in turn strategies that are valid and above all sustainable. Bearing in mind that sustainable development is that improvement in livelihoods of this earth's inhabitants that will not compromise the ability of future generations to meet their future needs.

The Journal of Petroleum and Environmental Biotechnology is therefore, in my considered and sober view, a well thought project and an endeavor that will catapult concern and zest in championing sustainable exploitation of petroleum resources in an enabling, secure setting (environment) allowing multiplication of benefits to mankind and animal-kind through responsible biotechnology.

All contributors and stakeholders to the Journal of Petroleum and Environmental Biotechnology are therefore agents of positive change and should take pride is taking sustainable development to the next level through this periodic open access publication. Take pride therefore in that realization and do not look back, keep moving forward, write the future today. Do not be discouraged by the problems of today and yesteryear i.e. world depressions, recessions, socioeconomic and political challenges. Make full use of mathematics, physics, chemistry, and biology, administrative, philosophical and psychological power and drive to cause sustainable development for the present and future generations. Terms and words like credit crunch, corporate world downsizing, company layoffs, bankruptcy, insolvency, company closures, unemployment, conflict, poverty and disease should never be used as excuses. How can the world go broke? Collectively natural resources can neither be created no destroyed; they can only be transformed from one form to another. Unfortunately some of these resources are being transformed into useless products to man and animal-kind by locked them in destructive instruments like war machinery, weapons (guns, nuclear warheads). These are consumables stored for future destructive use.

Lastly let us look at the sun earth model. There is always solar energy coming from the sun to the earth with the same intensity. This intensity can only be subtracted through obstruction by clouds. When clouds obstruct light, the light shortage affects everyone in its path. So going back to the profit equation, who are the clouds that obstruct petroleum wealth from benefiting all on our planet?

*Corresponding author: Irvin DT Mpofu, Animal Science Department, University of Namibia, Namibia, E-mail: impofu66@yahoo.com

Received August 21, 2012; Accepted August 21, 2012; Published August 26 , 2012

Citation: Mpofu IDT (2012) What does Petroleum, Environment and Biotechnology means to us vis a vis the Profit Equation? J Pet Environ Biotechnol 3:e110. doi:10.4172/2157-7463.1000e110

Copyright: (c) 2012 Mpofu IDT. This is an open-access article distributed unde the terms of the Creative Commons Attribution License, which permits unrestricted use, distribution, and reproduction in any medium, provided the original author and source are credited. 